\title{
Prevalence and Factors Influencing Eye Injuries among Welders in Accra, Ghana
}

\author{
Karl Kafui Kwaku Tetteh, ${ }^{1}$ Richard Owusu, ${ }^{2}$ and Wisdom Kudzo Axame $\mathbb{D}^{2}$ \\ ${ }^{1}$ Health Policy Planning and Management Department, School of Public Health, University of Ghana, P.O. Box LG 25, Legon, \\ Greater Accra Region, Ghana \\ ${ }^{2}$ Epidemiology and Biostatistics Department, School of Public Health, University of Health and Allied Sciences, PMB 31, Ho, \\ Volta Region, Ghana \\ Correspondence should be addressed to Wisdom Kudzo Axame; wisdomaxame@gmail.com
}

Received 10 June 2020; Revised 30 August 2020; Accepted 2 September 2020; Published 16 September 2020

Academic Editor: Diego A. S. Silva

Copyright (c) 2020 Karl Kafui Kwaku Tetteh et al. This is an open access article distributed under the Creative Commons Attribution License, which permits unrestricted use, distribution, and reproduction in any medium, provided the original work is properly cited.

\begin{abstract}
Background. Eye injuries are one of the most common work-related injuries among certain occupations, including welders. The aim of this study was to determine the prevalence and factors influencing eye injuries among welders in Accra, Ghana. Methods. In a cross-sectional study, we recruited 382 welders in Accra from two welding sites. Systematic sampling was used to select participants. A pretested semistructured questionnaire was used to collect demographic information, history of eye injuries, ownership, and use of eye protective equipment and workplace characteristics. Bivariate and multivariate logistic regressions at $5 \%$ level of significance were used to determine factors influencing eye injuries. Data were entered into Microsoft excel and exported to Stata 16/MP for analysis. Results. We found 59.7\% of welders engaged in electric/arc welding and $40.3 \%$ in gas welding. Overall prevalence of eye injuries was $47.9 \%$, higher among electric/arc welders (73.7\%) compared to gas welders (9.7\%). Factors associated with eye injuries were engaging in gas welding [AOR: 0.08, 95\% CI: 0.04-0.16], higher monthly income [AOR $=5.26$; 95\% CI: 1.72-16.09], nonuse of eye PPE while working [AOR $=1.86 ; 95 \%$ CI: 1.02-3.43], and no training on the use of eye personal protective equipment $[\mathrm{AOR}=2.17 ; 95 \% \mathrm{CI}: 1.07-4.38]$. Conclusion. There is high prevalence of welding-related eye injuries among electric welders. Gas welding, high monthly income, nonuse of eye protective equipment, and inadequate training on the use of eye protective equipment were significantly associated with eye injuries. Health policies should be implemented to ensure all welders use eye personal protective equipment.
\end{abstract}

\section{Introduction}

The eyes are the third most common organ affected by injuries apart from the hands and feet [1]. Eye injuries are common and constitute a major cause of preventable blindness. They are a common cause of visual morbidity occurring at workplaces worldwide [2]. About 2.5 million people succumb to eye injuries annually. Globally, more than 500,000 blinding injuries take place annually [3]. Eye injuries do not occur as random events. Majority of eye injuries have a direct link with occupation and the nature of activity at the time of the injury [1]. Some individuals have high risk of experiencing eye injuries because of their occupations. These individuals include small-scale and large-scale industrial workers. Welding, which involves cutting metal objects, soldering, and in some cases brazing [4], is one of such occupations that pose an exceptional risk to the eye [5]. Though the advent of urbanization and industrialization have brought about automation and mechanization, welding is still an important occupation, particularly in developing countries due to the slow pace of adaption of automated processes in these countries [4]. Industrialization is desirable for all countries. It assures higher standards of living for the citizenry. The welding industry is among the many establishments engaged in the business of producing goods and services. However, welders 
are susceptible to varied occupational health hazards. Welders form a high risk group for eye injury as a result of exposure to metals and ultraviolet radiations [6]. These exposures are considered to be major risk factors for eye disorders [7].

A study on the evaluation of occupational injuries among welders in Northwest Iran showed that 92\% of welders suffered from eye problems [8]. The occupational eye injuries welders experience is because of exposure to ocular hazards. Ocular hazards are elements and circumstances which are a threat to the maintenance and advancement of healthy, comfortable, and wholesome vision [3]. These ocular hazards include welding flash burns, flying metal objects, harmful metal fumes, particulate matter, and thermal burns $[2,9]$.

Different studies have reported various risk factors associated with eye injuries among welders. A study conducted in Ethiopia stated that poor working conditions, long periods of work, and inadequate safety precautions can lead to increased rates of ocular trauma and disease [10]. A study in India on occupational-related eye injuries reported that workers who were partially trained or have no training when exposed to welding were four times more likely to experience eye injuries compared to a trained worker [5].

The use of appropriate eye protection among welders prevents an estimated $90 \%$ of eye injuries [11]. Additionally, the use of appropriate protective eye wear during the welding process has been reported to reduce the harmful effects of infrared, visible, and ultraviolet radiation providing some form of mechanical protection for the eye from weld splatter there by reducing the intensity of visible light during welding $[11,12]$. Thus, the benefits of eye devices cannot be overemphasized.

Ghana has a large informal sector which makes up 70\% of its workforce [13]. Welding activities generally fall under the informal sector in the country. In Ghana, welders are vulnerable to occupational injuries and accidents because workplace safety is at a very low level due to lack of regulation and inspections, informal management structures, and lack of organizational safety culture [14]. Therefore, injuries associated with this profession could be damaging to the society and economy of the country as these informal sector workers help to mobilize capital and human resources.

Research efforts in relation to occupational health and safety issues in Ghana have been focused on mechanics [15] and woodworkers and the timber industry [16]. There is dearth of research on injuries, particularly eye injuries among welders in the country. Currently, not much is known about eye injuries among welders in Accra. The findings of this study would serve as a basis for advocacy regarding the reduction of eye injuries suffered by welders through welders' education, safety training, and welfare about eye care. This study, therefore, sought to address these identified gaps in research on eye injuries among welders in Accra. Considering the relatively high prevalence of eye injuries reported in some studies, this study is important to identify the prevalence and factors influencing eye injuries among welders in Accra.

\section{Materials and Methods}

2.1. Study Design and Setting. The study was a cross-sectional survey which was conducted in March 2019 to determine factors influencing eye injuries among welders in Accra. Our study was conducted at Agbogbloshie and Darkuman Cable and Wireless because they are very busy hubs for informal sector welding activities. These study sites are located in Accra, the capital of Greater Accra Region, Ghana. Agbogbloshie is an informal settlement with considerable overlap between industrial, commercial, and residential zones. It is known as the hotspot of e-waste recycling in the country. Agbogbloshie is separated by Abossey-Okai road and is an extended community as well as one of Ghana's largest urban slums [17]. It serves as home for informal workers and families. Darkuman Cable and Wireless has a mixture of residential buildings, wholesale, and retail shops, formal and informal offices, and workshops, as well as open expanses of informal activities including welding [18].

2.2. Sample Size. The required sample size was determined using a formula: $N=\left(Z^{2} \mathrm{pq} / e^{2}\right)$ by Cochran [19]. Assumptions were based on reliability coefficient $(z)$ of 1.96 at $95 \%$ confidence level, margin of error $(e)$ of $5 \%$, the proportion $(p)$ of $60.2 \%$ adopted from a study in Nigeria [9], and $q=(1-p=0.398)$. These figures were substituted into the formula to determine a required sample size for the study. The sample size that was obtained was increased by a nonresponse rate of 5\% based on Cochran's formula [19] proportion of population effect. With this, a sample size of 382 was obtained.

2.3. Sampling Procedure. Purposive sampling was used to select the two study sites in Accra: Agbogbloshie and Darkuman Cable and Wireless as they are well-known hubs of welding activities in the Accra Metropolitan Area. Proportionate sampling was used to determine the number of welders required at each site to achieve the required sample size. To do this, the total population of welders of the New Korle Lagoon Association of Welders (Agbogbloshie) and National Artisans and Traders Union of Ghana (NATUG), Darkuman Cable and Wireless branch, were used. These totals formed the sampling frame at each study site from which eligible welders were selected. At the study sites, systematic sampling was used to select the welders. To achieve this, a sampling interval $k$ was calculated at each site using $N / n$, where $N=$ population size and $n=$ sample size. For Agbogbloshie, $k=3$, after a random start, every third welder was selected until the calculated sample size was reached. For Darkuman Cable and Wireless, $k=5$, after a random start, every fifth welder was selected until the calculated sample size was reached. With this, 159 and 223 eligible welders were selected from the New Korle Lagoon Association of Welders (Agbogbloshie) and National Artisans and Traders Union of Ghana (Darkuman Cable and Wireless branch), respectively. 
2.4. Data Collection. A pretested semistructured questionnaire was used to obtain information on the sociodemographic characteristics, history of eye injury, welding types, and the use of personal protective equipment during welding activities. Data were collected through face-to-face interviews. This process was conducted in either English language or the local language of participants (Twi and Ga). Eligible participants were asked to give informed consent and allowed to participate in the study only after appending their signature or thumb prints to two copies of consent forms. Data were collected during working hours. Interviews were conducted in a safe area at the site away from any distractions.

2.5. Quality Control. Before data collection, the questionnaire was pretested outside the study sites, in a similar work environment.

2.6. Data Analysis and Management. Questionnaires from the field were coded and checked for consistency before passing on for data entry. Microsoft Excel 2016 was used for data entry. Data was exported to Stata 16/MP for analysis. Our primary analysis for the study was the proportion of welders admitting to have ever suffered any welding-related eye injury. Eye injury was described as any eye trauma, discomfort, or impaired vision as a result of welding activities. Secondary endpoint analysis was focused on age, sex, educational level, number of working years, income, welding type, and the use of eye PPE (independent variables). The use of eye PPE in this study was defined as continuous use of eye PPE such as face shields, impact googles, and general safety glasses while working. A master welder in this study was defined as the owner of a welding shop who supervises other welders in the same establishment and has the most experience on the job.Descriptive statistics was used for continuous and categorical variables.

Univariate and multivariate logistic regression analyses were used with the outcome variable (eye injuries) dichotomized as no $=0$ for no eye injury and yes $=1$ for eye injuries. The outcome of interest was eye injuries. The strength of associations between independent variables and eye injuries was determined using crude odds ratios (model I). Variables with $p$ values of $\leq 0.2$ in model I were considered for a stepwise multivariate logistic regression model (model II). To test for goodness of fit of model II, we used the likelihood ratio test to examine the likelihood of data under the full model as against the likelihood of the data under a model with reduced number of independent variables. We obtained a $p$ value for the overall model to be less than 0.05 . Thus, we concluded the model was good. Odds ratios and their respective $95 \%$ confidence intervals were calculated with $p$ values $<0.05$ considered statistically significant.

\section{Results and Discussion}

\subsection{Results}

3.1.1. Sociodemographic Characteristics of Respondents. Three hundred and eighty-two (382) welders were involved in this study. The mean age of study participants was
$32.6 \pm 10.96$ years (Table 1$)$. Less than half $(42.9 \%)$ were aged between 20 and 29 years. Majority (97.9\%) were males, and $67.8 \%$ had primary school education. Few $(30.2 \%)$ have been in the profession for 1 to 5 years, while $27.2 \%$ have been welding for 6 to 10 years. More (45.3\%) were masters, and $33.8 \%$ were apprentice with $20.9 \%$ being workers. Electric/ arc welding (59.7\%) was the most common welding type. More participants (55.2\%) work more than 12 hours daily. Some welders (42.7\%) earned between GHS 100 (\$18.86) and 500 (\$94.34) per month with $18.0 \%$ earning more than GHS 1000 per month (\$172.46).

3.1.2. Prevalence of Eye Injuries. Out of the 382 welders, selfreported eye injuries while welding were $47.9 \%$ (95\% CI: 42.8\%-53.0\%), as shown in Figure 1.

3.1.3. Characteristics of Eye Injuries. Among those who experienced eye injuries, a large proportion of the injuries (95.1\%) occurred less than a year ago. Most (59.6\%) of the injuries sustained occurred in the evening and majority $(95.6 \%)$ indicated the injuries lasted less than a month. More than half $(53.6 \%)$ of the injuries were chemical in nature, while only $10.4 \%$ were electrical. Most of the welders (83.6\%) reported the injuries they sustained affected both eyes (Table 2).

3.1.4. Distribution of Eye Injuries among Welding Types. Eye injuries among electric/arc welders were $73.7 \%$, while only $9.7 \%$ of gas welders stated they had ever suffered from eye injuries (Figure 2).

3.1.5. Ownership, Use of Eye PPE, and Workplace Characteristics. Majority (74.1\%) of the welders indicated they own an eye PPE. However, usage of eye PPE was 33.2\% (Table 3). The most common reason for nonownership of eye PPE was it being not necessary (86.9\%). Reasons given for nonuse of eye PPE included the use of eye PPE was not mandatory (58\%), eye PPE reduced productivity (22\%), and uncomfortable feeling (3.1\%). Few (17.5\%) of the welders have had training on the use of eye PPE; majority (96.9\%) had no workplace eye PPE policy at work and few (3.9\%) had safety training at work (Table 3). Almost all (91.1\%) stated they were always exposed to nearby welding activities.

3.1.6. Factors Associated with Eye Injuries among Welders. At the bivariate analysis, welding type, monthly income, the use of eye PPE while working, training on use of eye PPE, and exposure to nearby welding activities were associated with risk of eye injuries (Table 4). In the multivariate analysis, gas welders were $92 \%$ less likely to have eye injuries compared to their counterparts who engage in electric/arc welding [AOR: 0.08, 95\% CI: 0.04-0.16]. Increasing income increased the likelihood of eye injuries. Welders who earn more than GHS 1000 were 5 times more likely to experience eye injuries compared to those who earn less than GHS 100 [AOR: 5.26, 95\% CI: 1.72-16.09]. Welders who did not use 
TABLE 1: Background characteristics of welders $(N=382)$.

\begin{tabular}{|c|c|c|}
\hline Characteristics & Frequency & Percentage (\%) \\
\hline $\begin{array}{l}\text { Age (years), mean }( \pm S D) \\
\quad<20 \\
20-29 \\
30-39 \\
49-49 \\
50-59 \\
\geq 60\end{array}$ & $\begin{array}{c}32.6( \pm 10.96) \\
23 \\
164 \\
103 \\
54 \\
27 \\
11 \\
\end{array}$ & $\begin{array}{c}6.0 \\
42.9 \\
27.0 \\
14.1 \\
7.1 \\
2.9 \\
\end{array}$ \\
\hline $\begin{array}{l}\text { Sex } \\
\text { Male } \\
\text { Female }\end{array}$ & $\begin{array}{c}374 \\
8\end{array}$ & $\begin{array}{c}97.9 \\
2.1\end{array}$ \\
\hline $\begin{array}{l}\text { Education } \\
\text { No formal education } \\
\text { Primary } \\
\text { Secondary } \\
\text { Tertiary }\end{array}$ & $\begin{array}{c}31 \\
259 \\
83 \\
9\end{array}$ & $\begin{array}{c}8.1 \\
67.8 \\
21.7 \\
2.4\end{array}$ \\
\hline $\begin{array}{l}\text { Working experience (years), } \\
\text { mean }( \pm \mathrm{SD}) \\
\quad<1 \\
1-5 \\
6-10 \\
>10\end{array}$ & $\begin{array}{c}10.1( \pm 8.65) \\
20 \\
115 \\
104 \\
143\end{array}$ & $\begin{array}{c}5.2 \\
30.2 \\
27.2 \\
37.4\end{array}$ \\
\hline $\begin{array}{l}\text { Type of welder } \\
\text { Apprentice } \\
\text { Worker } \\
\text { Master } \\
\end{array}$ & $\begin{array}{c}129 \\
80 \\
173 \\
\end{array}$ & $\begin{array}{l}33.8 \\
20.9 \\
45.3 \\
\end{array}$ \\
\hline $\begin{array}{l}\text { Welding type } \\
\text { Electric/arc welding } \\
\text { Gas welding }\end{array}$ & $\begin{array}{l}228 \\
154 \\
\end{array}$ & $\begin{array}{l}59.7 \\
40.3 \\
\end{array}$ \\
\hline $\begin{array}{l}\text { Daily working hours } \\
\quad<12 \text { hours } \\
\geq 12 \text { hours } \\
\end{array}$ & $\begin{array}{l}171 \\
211 \\
\end{array}$ & $\begin{array}{l}44.8 \\
55.2 \\
\end{array}$ \\
\hline $\begin{array}{l}\text { Monthly income (GHS) } \\
\quad<100 \\
100-500 \\
600-1000 \\
>1000\end{array}$ & $\begin{array}{c}66 \\
163 \\
84 \\
69\end{array}$ & $\begin{array}{l}17.3 \\
42.7 \\
22.0 \\
18.0\end{array}$ \\
\hline
\end{tabular}

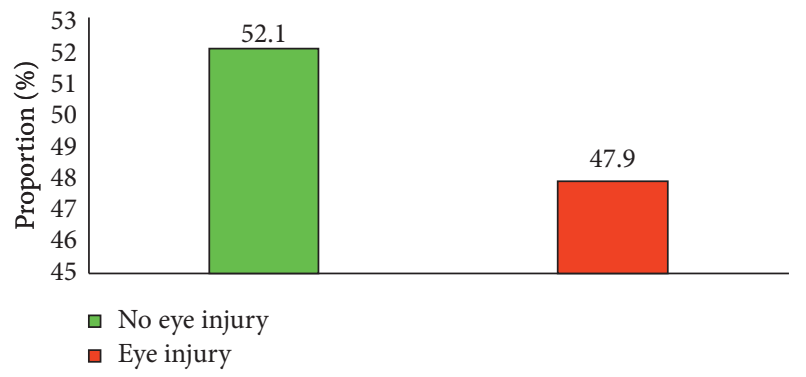

FIGURE 1: Overall distribution of self-reported eye injuries among welders in the study.

eye PPE were $86 \%$ more likely to experience eye injuries compared to their counterparts who use eye PPE [AOR: 1.86, 95\% CI: 1.03-3.33]. Not being trained on how to use eye PPE increased the likelihood of experiencing eye injuries by 2fold [AOR: 2.17, 95\% CI: 1.07-4.38].
TABLE 2: Characteristics of eye injuries among welders $(N=183)$.

\begin{tabular}{lcc}
\hline Variable & Frequency & Percentage (\%) \\
\hline Period of last eye injury & & \\
Less than a year ago & 174 & 95.1 \\
$\quad$ More than a year ago & 9 & 4.9 \\
\hline Time of day of last injury & & \\
$\quad$ Morning & 35 & 19.1 \\
Afternoon & 39 & 21.3 \\
$\quad$ Evening & 109 & 59.6 \\
\hline Duration of eye injury & & \\
Less than a month & 175 & 95.6 \\
$\quad$ More than a month & 8 & 4.4 \\
\hline Nature of eye injury & & \\
Mechanical & 39 & 21.3 \\
Chemical & 98 & 53.6 \\
Thermal & 27 & 14.7 \\
Electrical & 19 & 10.4 \\
\hline Number of eyes affected & & \\
$\quad$ One eye & 30 & 83.6 \\
Both eyes & 153 & \\
\hline
\end{tabular}

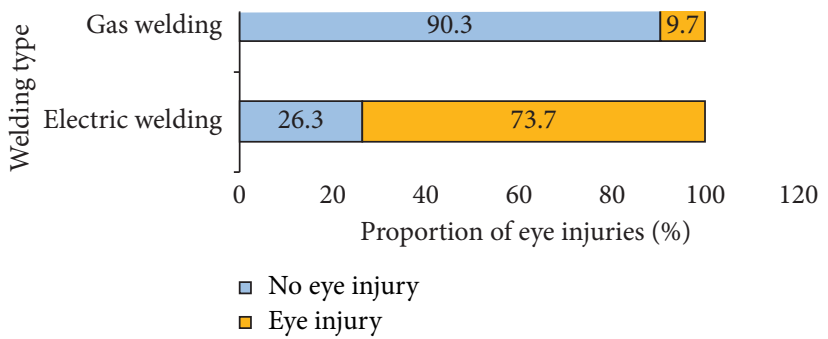

Figure 2: Distribution of self-reported eye injuries among respondents based on welding type.

\section{Discussion}

This study sought to determine the prevalence and factors influencing eye injuries among welders in Accra. Overall, the study found the prevalence of reported eye injury among welders in Accra to be $47.9 \%$. This is similar to the results obtained in a study conducted in Nigeria by Ihekaire who found the prevalence of eye injury among welders to be $48 \%$ [3]. However, this prevalence of is lower compared to $84.5 \%$ by Nwala in Nigeria [6], 75\% by Ganesh Kumar in India [20], and $61 \%$ by Sithole in South Africa [21]. Nwala attributed the high prevalence to increasing industrialization [6], and Sithole attributed their observation to poor knowledge on the adverse effects of welding activities [21]. The prevalence of eye injuries reported in our study could be attributed to the low use of eye PPE. Almost half of welders were found to have suffered from eye injuries. This could have serious socioeconomic consequences for their families, communities, and the country as a whole especially if these injuries are severe and/or permanent, affecting the income generating capability of the welder.

We also found that electric arc welding is the dominant welding type used by welders in Accra (59.7\%). A similar pattern was observed in other studies where arc welding was the most common welding type used compared to gas 
TABLE 3: Ownership, use of eye PPE, and workplace characteristics.

\begin{tabular}{|c|c|c|}
\hline Variable & Frequency & $\begin{array}{c}\text { Percentage } \\
(\%)\end{array}$ \\
\hline \multicolumn{3}{|l|}{ Own eye PPE } \\
\hline No & 99 & 25.9 \\
\hline Yes & 283 & 74.1 \\
\hline \multicolumn{3}{|l|}{ Reasons for nonownership of eye PPE } \\
\hline Not necessary & 86 & 86.9 \\
\hline Too expensive & 8 & 8.1 \\
\hline Do not know where to get one & 5 & 5.0 \\
\hline \multicolumn{3}{|l|}{ Usage of eye PPE while working } \\
\hline Nonuse & 255 & 66.8 \\
\hline Use & 127 & 33.2 \\
\hline \multicolumn{3}{|l|}{ Commonly used eye PPE } \\
\hline Glasses & 57 & 44.9 \\
\hline Goggles & 51 & 40.2 \\
\hline Eye shields & 14 & 11.0 \\
\hline Others & 5 & 3.9 \\
\hline \multicolumn{3}{|l|}{ Reasons for nonuse of eye PPE } \\
\hline Use of eye PPE not mandatory & 148 & 58.0 \\
\hline Reduces productivity & 56 & 22.0 \\
\hline Low risk of task & 22 & 8.6 \\
\hline Feels uncomfortable & 8 & 3.1 \\
\hline In a hurry & 8 & 3.1 \\
\hline Produces heat & 5 & 2.0 \\
\hline Forgetfulness & 5 & 2.0 \\
\hline Short duration of task & 3 & 1.2 \\
\hline \multicolumn{3}{|l|}{ Training on use of eye PPE } \\
\hline No & 315 & 82.5 \\
\hline Yes & 67 & 17.5 \\
\hline \multicolumn{3}{|l|}{ Workplace eye PPE policy } \\
\hline Present & 13 & 3.4 \\
\hline Absent & 369 & 96.6 \\
\hline \multicolumn{3}{|l|}{ Safety training at work } \\
\hline Never & 301 & 78.8 \\
\hline Sometimes & 66 & 17.3 \\
\hline Often/always & 15 & 3.9 \\
\hline \multicolumn{3}{|l|}{ Exposure to nearby welding activities } \\
\hline Never & 12 & 3.1 \\
\hline Sometimes & 22 & 5.8 \\
\hline Often/always & 348 & 91.1 \\
\hline
\end{tabular}

welding $[22,23]$. The popularity of arc welding observed in these studies could be attributed to its cost effectiveness, its availability, and ease of use. Among electric welders, $73.7 \%$ of them experienced eye injuries, while only $9.7 \%$ of gas welders suffered from eye injuries. This agrees with a study by Nartey et al. [23] which found electric welding to be more hazardous. This may be due to the nature of electric welding since it emits a higher ultraviolet light and a brighter flame [24].

The current study found that only $33 \%$ of welders used eye PPE while working. This is in agreement with two studies conducted in South Africa [25] and Nigeria [26]. A study reported by Ajayi and Omotoye [27] also reported low usage of eye PPE, as did by Abu et al. [15]. This study reported a higher usage of $33 \%$ as compared to that reported by Abu [15] (27.5\%). However, this is lower than $47.7 \%$ usage of eye PPE which was reported in Nepal [28]. Interestingly enough,
$74.1 \%$ stated that they own eye PPEs. This is a clear indication that ownership of eye PPE does not necessarily translate into usage. This is also seen in a study by Ajayi which reported that, while $45.9 \%$ of welders possessed eye PPE, only 9.6\% use eye PPEs all the time [12]. Low use of eye PPE could be attributed to a variety of reasons. Reasons for nonuse identified in this study were reduction in productivity, inconvenience, production of excessive heat, forgetfulness, short duration of task, anticipated low risk of task, and time factor. Some of these reasons are similar to what was reported by Lombardi et al. [29]. These reasons may be categorized broadly as perceptions of hazard and risks, barriers to PPE usage, and enforcement and reinforcement. Another possible factor could be limited knowledge about the importance of PPE. The observed pattern of PPE use among welders in this study suggests an increased risk of eye injuries among welders in Ghana. This is because it has been reported that unsafe occupational acts such as nonuse of PPE are widely associated with injuries $[7,30]$. This observation warrants government institutions responsible for Occupational Health and Safety to enforce mandatory use of PPE to ensure welders are more attentive towards personal safety. Without enforcement, eye PPE use is left to the discretion of the employer and employee. Enforcement should be accompanied by positive reinforcement from supervisors and colleagues to ensure the sustainability of eye PPE use. Also, better acceptance of safety procedures will be gained by involving all stakeholders, including workers, by how work tasks should be performed and using the tools necessary to achieve it [29]. The study observed variations in the types of eye PPE used by welders. Most of the eye PPEs were locally manufactured to no set standard. Thus, some of the eye PPEs used were not adequate to help protect against eye injuries. This could have also contributed to the high prevalence of eye injuries.

This study identified a significant association between the nonuse of eye PPE, welding type, monthly income greater than GHS 1000 (\$172.46), no training on the use of eye PPE, and eye injuries among welders.

Welders who did not use eye PPE while working were almost twice at risk of eye injuries. This is consistent with similar studies in Nigeria [3] and Nepal [31] where it was reported that nonuse of eye PPE was significantly associated with eye injuries. The primary purpose of any personal protective equipment is to protect the user against health or safety risks at work. In this context, eye PPEs serve as a barrier between the eyes and the external environment. Thus, the use of eye PPE protects the user's eyes from potential chemical, radiological, or mechanical irritants and hazards. Suffice it to say that welders who did not use eye PPE in this study lacked this protection, and this could have contributed to their increased likelihood of experiencing eye injuries.

We also found that gas welders in this study were less likely to experience eye injuries compared to electric/arc welders. An earlier study reported electric/arc welding to be more hazardous than gas welding [32]. Electric welding involves the use of voltage and generates high temperatures which may cause life-threatening injuries. Additionally, 
TABLE 4: Factors associated with eye injuries among welders.

\begin{tabular}{|c|c|c|c|c|c|}
\hline \multirow{2}{*}{ Variable } & \multirow{2}{*}{ Eye injury $n(\%)$} & \multicolumn{2}{|c|}{ Model I COR } & \multicolumn{2}{|c|}{ Model II AOR } \\
\hline & & OR $(95 \% \mathrm{CI})$ & $p$ value & OR $(95 \% \mathrm{CI})$ & $p$ value \\
\hline Age (years) & & & 0.3813 & & \\
\hline$<20$ & $9(4.9)$ & 1 & & & \\
\hline $20-29$ & $81(44.3)$ & $0.66(0.27-1.60)$ & & & \\
\hline $30-39$ & $42(22.9)$ & $0.93(0.37-2.35)$ & & & \\
\hline $49-49$ & $31(16.9)$ & $0.48(0.18-1.29)$ & & & \\
\hline $50-59$ & $14(7.6)$ & $0.60(0.19-1.84)$ & & & \\
\hline$\geq 60$ & $6(3.3)$ & $0.54(0.12-2.29)$ & & & \\
\hline Educational level & & & 0.6860 & & \\
\hline No formal education & $13(7.1)$ & 1 & & & \\
\hline Primary & $125(68.3)$ & $1.29(0.61-2.74)$ & & & \\
\hline Secondary & $42(22.9)$ & $1.42(0.62-3.26)$ & & & \\
\hline Tertiary & $3(1.6)$ & $0.69(0.15-3.29)$ & & & \\
\hline Working experience (years) & & & 0.6450 & & \\
\hline$<1$ & $8(4.4)$ & 1 & & & \\
\hline $1-5$ & $56(30.6)$ & $0.70(0.27-1.85)$ & & & \\
\hline $6-10$ & $46(25.1)$ & $0.84(0.32-2.23)$ & & & \\
\hline$>10$ & $73(39.9)$ & $0.64(0.25-1.66)$ & & & \\
\hline Welding type & & & $<0.001$ & & \\
\hline Electric/arc welding & $168(91.8)$ & 1 & & 1 & \\
\hline Gas welding & $15(8.2)$ & $0.04(0.02-0.07)$ & & $0.08(0.04-0.16)$ & $<0.001^{*}$ \\
\hline Monthly income (GHS) & & & 0.2064 & & \\
\hline$<100$ & $32(17.5)$ & 1. & & 1 & \\
\hline $100-500$ & $82(44.8)$ & $1.07(0.61-1.90)$ & & $1.27(0.60-2.70)$ & 0.529 \\
\hline $600-1000$ & $32(17.5)$ & $0.65(0.34-1.26)$ & & $1.49(0.58-3.79)$ & 0.407 \\
\hline$>1000$ & $37(20.2)$ & $1.23(0.62-2.41)$ & & $5.26(1.72-16.09)$ & $0.004^{*}$ \\
\hline Usage of eye PPE while working & & & 0.0877 & & \\
\hline Use & $53(29.0)$ & 1 & & & \\
\hline Nonuse & $130(71.0)$ & $1.45(0.944-2.23)$ & & $1.86(1.03-3.33)$ & $0.040^{*}$ \\
\hline Training on use of eye PPE & & & 0.1867 & & \\
\hline Yes & $37(20.2)$ & 1 & & 1 & \\
\hline No & $146(79.8)$ & $1.43(0.84-2.42)$ & & $2.17(1.07-4.38)$ & $0.030^{*}$ \\
\hline Eye PPE policy at work & & & 0.009 & & \\
\hline Present & $12(6.6)$ & 1 & & 1 & \\
\hline Absent & $171(93.4)$ & $9.64(1.75-53.10)$ & & $0.05(0.01-1.39)$ & 0.077 \\
\hline Safety training at work & & & 0.811 & & \\
\hline Never & $142(77.6)$ & 1 & & & \\
\hline Sometimes & $34(18.6)$ & $1.19(0.70-2.03)$ & & & \\
\hline Often/always & $7(3.8)$ & $0.98(0.35-2.77)$ & & & \\
\hline Exposure to nearby welding activities & & & 0.0001 & & \\
\hline Never & $3(1.6)$ & 1 & & 1 & \\
\hline Sometimes & $2(1.1)$ & $0.3(0.04-2.11)$ & & $0.08(0.01-1.08)$ & 0.057 \\
\hline Often/always & $178(97.3)$ & $3.144(1.84-11.80)$ & & $1.22(0.23-6.58)$ & 0.813 \\
\hline
\end{tabular}

${ }^{*}$ Statistically significant at $p$ value $<0.05$.

continuous exposure to this type of welding can lead to arc eye, a condition in which ultraviolet light inflames the cornea or even burns the retina of the eyes [33]. This could have been the reason why gas welders had reduced odds of welding-related eye injuries.

Our study found that welders with no training on the use of eye PPE were 2 times more likely to experience eye injuries compared to their counterparts with training. Training on the use of eye PPE was provided by the master who has gained experience in the profession over the years to the apprentice and worker welders. These training included the types and correct use of eye PPE while welding. The presence of eye PPE documentations observed in some welding sheds state the continuous use of eye PPE while working also complements master welders in training their subordinates at the workplace. This finding resonates with what was found in India where welders with institutional training on eye PPE were less likely to develop eye injuries [20]. The reason for the reduced odds among welders who have had training on eye PPE could be attributed to increased awareness and knowledge about occupational health and safety [2].

We found that increasing income increased the likelihood of experiencing eye injuries. This finding is similar to a study in Kenya among workers, including welders, which reported that higher income workers take on more jobs and, 
in their haste to perform these jobs, develop more eye injuries [34]. Also, the higher risk of eye injuries among welders with high monthly income of more than GHS 1000 (\$172.46) may be because they undertake more challenging and riskier tasks to earn more money.

\section{Conclusion}

Almost half of the welders have sustained eye injury before. Most of the eye injuries affected both eyes. Majority of welders use electric welding in their activities. Those who use electric welding are more prone to eye injuries compared to gas welders. Usage of eye PPEs is relatively low among welders for a variety of reasons, including the primary reason that usage of eye PPEs is not mandatory. The study found that the welders who do not use eye PPEs have a higher risk of eye injuries. Also, most welders have no form of safety training at work. Increasing income increased the risk of eye injuries.

\section{Recommendations}

Considering the importance of eye PPEs in the prevention of eye injuries, the use of eye PPEs by welders should be increased through education and training on the use of eye PPE, making the use of eye PPE mandatory. These should be implemented through the relevant welder associations. Welding associations should prioritize interventions to reduce eye injuries particularly among electric welders since they form the majority of welders who suffer more eye injuries. There is also a need to conduct further studies using both quantitative and qualitative methods to include all kinds of welders to obtain results generalizable to the welding community.

\section{Limitation}

Despite the important findings made in our study, it is worth noting the possible limitations inherent in its conduct. Our results were premised on responses provided by participants based on events which occurred in the past (though not too distant). There is therefore the possibility of recall bias. Our study did not include other types of welders such as industrial welders in order to generalize findings to the welding community. It is however important to note that these potential limitations do not affect the validity and reliability of our findings in any way.

\section{Abbreviations}

PPE: $\quad$ Personal protective equipment

NATUG: National Artisans and Traders Union of Ghana

AOR: $\quad$ Adjusted odds ratio

GHS/ERC: Ghana Health Service Ethics Review

Committee.

\section{Data Availability}

All data and materials are available upon reasonable request from the corresponding author.

\section{Ethical Approval}

Ethical approval for the study was obtained from the Ghana Health Service Ethics Review Committee (GHS/ERC: 036/ 02/19). Permission was also obtained from the New Korle Lagoon Association of Welders (Agbogbloshie) and National Artisans and Traders Union of Ghana (NATUG), Darkuman Cable and Wireless branch.

\section{Consent}

Each respondent was informed prior to the interview that they are under no obligation to take part, they could withdraw at any time, and all answers were treated with paramount confidentiality. All welders who agreed to be part of the study were required to sign an informed consent form before being interviewed.

\section{Disclosure}

This study received no funding. All study activities were funded by the authors.

\section{Conflicts of Interest}

The authors declare that they have no conflicts of interest.

\section{Authors' Contributions}

KKKT conceived and designed the study and wrote the first draft of the manuscript. WKA analysed the data, contributed to literature search, reviewed the manuscript, and wrote the draft of the manuscript. RO reviewed the first draft of the manuscript. All authors read and approved the final manuscript.

\section{Acknowledgments}

The authors thank the various welders at the study sites for providing us their time in order to conduct this study. The authors are also grateful to the New Korle Lagoon Association of Welders (Agbogbloshie) and National Artisans and Traders Union of Ghana (NATUG), Darkuman Cable and Wireless branch.

\section{References}

[1] M. D. Mir, A. Jehan, S. S. Qadri, R. M. Wani, H. Bashir, and T. Shafi, "An epidemiological study on prevalence and pattern of ocular injuries in kashmir valley-a conflict zone," International Journal of Medical Science and Public Health, vol. 3, no. 3, pp. 3-6, 2014.

[2] M. Prabhu, R. Rokhade, K. R. P. Chandra, and A. Kakhandaki, "A study of awareness and use of personal protective eyewear among welders in a tier 2 city in South India," Indian Journal of Clinical and Experimental Ophthalmology, vol. 3, no. 3, pp. 356-360, 2017.

[3] D. E. Ihekaire, C. S. Orji, and C. S. Oji, "Corneal injuries associated with ocular hazards in the welding Industry: a case study of nekede mechanic village nekede, imo state, Nigeria," International Journal of Ophthalmology \& Visual Science, vol. 2, no. 2, pp. 37-54, 2017. 
[4] American Welding Society, Personal Protective Equipment (PPE) for Welding and Cutting. Safety and Health Fact Sheet No. 33, American Welding Society, Miami, FL, USA, 2008.

[5] S. G. Kumar, A. Dharanipriya, and S. S. Kar, "Awareness of occupational injuries and utilization of safety measures among welders in coastal south India," The International Journal of Occupational and Environmental Medicine, vol. 4, no. 4, pp. 172-177, 2013.

[6] O. R. Nwala, C. Ahuamaokezie, N. C. Ikoro, Y. C. Azuamah, and M. Ohiri, "Ocular injuries among welders in A rural community in Nigeria," Internet Research, vol. 1, no. 11, pp. 1-11, 2014.

[7] "OSHA. Recommended practices for safety and health programs in construction," Occupational Safety and Health Administration, vol. 10, no. 1, pp. 1-40, 2016.

[8] F. Amani, M. Bahadoram, and S. Hazrati, "Evaluation of occupational injuries among welders in Northwest Iran," Journal of Preventive Epidemiology, vol. 2, no. 2, pp. 1-5, 2017.

[9] B. Fiebai and E. A. Awoyesuku, "Ocular injuries among industrial welders in Port Harcourt, Nigeria," Clinical Ophthalmology, vol. 5, pp. 1261-1263, 2011.

[10] Z. Addisu, "Pattern of ocular trauma seen in grarbet hospital, butajira, Central Ethiopia," Ethiopian Journal of Health Development, vol. 25, no. 2, pp. 150-155, 2011.

[11] A. S. Pabley and A. H. Keeney, "Welding processes and ocular hazards and protection," American Journal of Ophthalmology, vol. 92, no. 1, pp. 77-84, 1981.

[12] I. A. Ajayi, A. O. Adeoye, C. O. Bekibele, and O. H. Onakpoya, "Awareness and utilization of protective eye device among welders in a southwestern Nigeria community," Annals of African Medicine, vol. 10, no. 4, pp. 7-12, 2011.

[13] E. Clarke, "Small-scale enterprises and the informal economy," African Newsletter on Occupational Health and Safety, vol. 22, no. 2, pp. 1-2, 2012.

[14] E. Clarke, Do Occupational Health Services Really Exist in Ghana? A Special Focus on the Agricultural and Informal Sectors, Ghana Health Service, Accra, Ghana, 2005.

[15] E. K. Abu, S. Bert, B. Kusi et al., "Ocular health and safety assessment among mechanics of the cape coast metropolis, Ghana," Journal of Ophthalmic and Vision Research, vol. 11, no. 1, pp. 2-7, 2016.

[16] G. Dwomoh, E. E. Owusu, and M. Addo, "Impact of occupational health and safety policies on employees' performance in Ghana's timber industry: evidence from lumber and logs limited," International Journal of Educational Research, vol. 1, no. 10, pp. 1-14, 2013.

[17] K. Daum, J. Stoler, and R. J. Grant, "Toward a more sustainable trajectory for e-waste policy: a review of a decade of e-waste research in Accra, Ghana," International Journal of Environmental Research and Public Health, vol. 14, no. 135, pp. 1-18, 2017.

[18] M. Oteng-ababio, "Electronic waste management in Ghana - issues and practices," in Sustainable Development - Authoritative and Leading Edge Content for Environmental Management, pp. 149-166, Intechopen Publisher, London, UK, 2012.

[19] W. G. Cochran, Sampling Techniques, John Wiley \& Sons, New York, NY, USA, 3rd edition, 1977.

[20] S. Ganesh Kumah, A. Dharanipriya, S. Ganesh Kumar, and A. Dharanipriya, "Prevalence and pattern of occupational injuries at workplace among welders in coastal south India," Indian Journal of Occupational and Environmental Medicine, vol. 18, no. 3, pp. 135-139, 2014.

[21] H. L. Sithole, O. A. Oduntan, and M. O. Oriowo, "Eye protection practices and symptoms among welders in the
Limpopo Province of South Africa," African Vision and Eye Health Journal, vol. 68, no. 3, pp. 130-136, 2009.

[22] E. Adu and A. Danquah, "Welding practices in selected metal welding industries in Ghana," International Journal of Scientific and Engineering, vol. 7, no. 6, pp. 462-473, 2016.

[23] A. Nartey, M. P. Tchiakpe, E. Kobia-Acquah, S. AnkamahLomotey, and B. A. Ankrah, "Eye injuries among heavy industries in tema metropolis, Ghana," International Journal of Development Research, vol. 7, no. 10, pp. 16108-16114, 2017.

[24] K. G. Davies, U. Asana, O. C. Nku, and E. E. Osim, "Ocular effects of chronic exposure to wielding light on Calabar welders," Nigerian Journal Of Physiological Sciences, vol. 22, no. 2, pp. 1-5, 2010.

[25] V. N. Sukati, "Occupational health southern africa-workplace eye injuries: a literature review," Occupational Health and Safety Act, vol. 20, no. 3, pp. 18-22, 2014, [Internet].

[26] B. L. Tanko and N. A. Anigbogu, "The use of personal protective equipment (PPE) on construction sites in Nigeria," in Proceedings of the 4th West Africa Built Environment Research (WABER) Conference, S. Laryea, S. A. Agyepong, R. Leiringer, and W. Hughes, Eds., pp. 1341-1348, Abuja, Nigeria, July 2012.

[27] I. A. Ajayi and O. J. Omotoye, "Pattern of eye diseases among welders in a Nigeria community," African Health Sciences, vol. 12, no. 2, pp. 210-216, 2012.

[28] S. S. Budhathoki, S. B. Singh, R. A. Sagtani, S. R. Niraula, and P. K. Pokharel, "Awareness of occupational hazards and use of safety measures among welders: a cross-sectional study from Eastern Nepal," BMJ Open, vol. 4, Article ID e004646, 2014.

[29] D. A. Lombardi, S. K. Verma, M. J. Brennan, and M. J. Perry, "Factors influencing worker use of personal protective eyewearfluencing worker use of personal protective eyewear," Accident Analysis \& Prevention, vol. 41, no. 4, pp. 755-762, 2009.

[30] K. E. Ogundipe, J. D. Owolabi, and E. A. Olanipekun, "Factors affecting effective use of safety wears among construction site Operatives: lessons from indigenous firms in south western Nigeria," International Journal of Applied Engineering Research, vol. 13, no. 6, pp. 4314-4325, 2018.

[31] A. Ghimire, S. S. Budhathoki, S. R. Niraula, A. Shrestha, and P. K. Pokharel, "Work-related injury among welders working in metal workshops of dharan municipality, Nepal," Journal of Nepal Health Research Council, vol. 16, no. 2, pp. 156-159, 2018.

[32] P. Vecchia, M. Hietanen, B. E. Stuck, E. V. Deventer, and S. Niu, Protecting Workers from Ultraviolet Radiation, WHO, Geneva, Switzerland, 2007.

[33] H. B. Cary and S. C. Helzer, Modern Welding Technology, Pearson Education, Upper Saddle River, NJ, USA, 2005.

[34] A. C. Chepkener, Knowledge, Attitude and Practice of Eye Safety Among Jua Kali Industry Workers in Nairobi, University of Nairobi, Nairobi, Kenya, 2013. 